\title{
Oficinas educativas de nutrição como estratégia para a promoção de modos de vida saudável ${ }^{1}$
}

\author{
Marlene Azevedo Magalhães Monteiro - http://orcid.org/0000-0002-7539-40892 \\ Liliane Nunes da Silva - http://orcid.org/0000-0001-7773-18113 \\ Amanda Márcia dos Santos Reinaldo - http://orcid.org/0000-0003-0283-23134
}

\section{RESUMO}

O transtorno psiquiátrico implica em dificuldades de cunho individual, familiar e social. Em Belo Horizonte, têm destaque, na rede de serviços substitutivos ao hospital psiquiátrico, os Centros de Convivência, que constituem um dos serviços que contribuem para a construção do projeto de inserção das pessoas com transtorno psiquiátrico na sociedade. 0 artigo se propõe a divulgar os resultados do projeto de extensão "Educação nutricional para portadores de sofrimento mental em um Centro de Convivência", cujo objetivo foi avaliar a efetividade das oficinas educativas de nutrição realizadas em um Centro de Convivência para pessoas com transtorno psiquiátrico no município de Belo Horizonte, Minas Gerais. Realizaram-se entrevistas estruturadas com os participantes das oficinas educativas de nutrição, buscando entender o impacto do projeto na promoção de hábitos de vida saudável das pessoas com transtorno psiquiátrico. As oficinas educativas foram realizadas semanalmente sobre temas relacionados à saúde, à alimentação e à nutrição com utilização de técnicas lúdico-pedagógicas. Os resultados das entrevistas foram tabulados e a análise de conteúdo efetuada. No período de 2008 a 2016, executaram-se 97 oficinas educativas, com a participação de 582 usuários ao todo, numa média de seis participantes por oficina. A faixa etária dos participantes foi de 25 a 60 anos. Observaram-se melhorias nos hábitos alimentares dos participantes das oficinas educativas de nutrição do Centro de Convivência.

Palavras-chave: saúde mental; educação alimentar e nutricional; oficinas educativas; promoção da saúde.

\footnotetext{
${ }^{1}$ Ação extensionista aprovada pelo Comitê de Ética em Pesquisa da Universidade Federal de Minas Gerais sob o parecer 37574914.3.0000.5149.

2 Doutora em Ciência e Tecnologia de Alimentos, Departamento de Nutrição, Escola de Enfermagem, Universidade Federal de Minas Gerais - UFMG. E-mail: marleneaz@enf.ufmg.br

${ }^{3}$ Graduanda em Nutrição, Universidade Federal de Minas Gerais - UFMG. E-mail: lilly.nunes@gmail.com

4 Doutora em Enfermagem Psiquiátrica, Departamento de Enfermagem Aplicada, Escola de Enfermagem, Universidade Federal de Minas Gerais - UFMG. E-mail: amandamsreinaldo@gmail.com
} 


\section{Educational nutrition workshops as a strategy for promoting healthy lifestyles}

\section{ABSTRACT}

Psychiatric disorder implies difficulties of individual, family, and social nature. The Community Centers in Belo Horizonte stand out in the network of services that substitute psychiatric institutionalization. The Community Centers services contribute for the construction of the project for the insertion of people with psychiatric disorder into society. The purpose of this article is to disseminate the results of the community outreach project named "Nutritional education for people with psychiatric disorder in a Community Center, through evaluation of the effectiveness of the educational workshops. The project was held at a Community Center in Belo Horizonte city, Minas Gerais and attended by people with psychiatric disorder. Structured interviews were carried out with the participants of the educational nutrition workshops, seeking to understand the impact of the project on the promotion of healthy lifestyle for people with psychiatric disorder. Educational workshops were held weekly on topics related to health, food and nutrition using ludic-pedagogical techniques. The results of the interviews were tabulated, and the content analysis was performed. Ninety-seven educational workshops were held between 2008 and 2016. The total number of participants was 582, with an average of six attendees per workshop, whose age ranged from 25 to 60 . It was observed improvement in the eating habits of the participants in the educational nutrition workshops at the Community Center.

KEYWORDS: health education; mental health; food and nutrition education; educational workshops; health promotion.

\section{INTRODUÇÃO}

O transtorno psiquiátrico implica em dificuldades de cunho individual, familiar e social. 0 curso crônico da doença e a incapacidade que, em alguns casos, acompanha a pessoa demandando recursos socioeconômicos e investimento público considerável, especialmente em países cujo desenvolvimento está associado à questão da baixa renda per capita e educacional (RAZZOUK, 2013).

A Organização Mundial de Saúde (2002) define a Saúde Mental como "um estado de bem-estar no qual o indivíduo é capaz de usar suas próprias habilidades, recuperar-se do estresse rotineiro, ser produtivo e contribuir com a sua comunidade". Esse "estado de bem-estar" é direito de todas as pessoas e as formas de atingi-lo serão sempre múltiplas e não excludentes entre si.

A Reforma Psiquiátrica Brasileira, na década de 80, conseguiu colocar a desinstitucionalização na agenda de trabalho das políticas destinadas à saúde mental, propondo alternativas à internação e, gradativamente, substituir o hospital psiquiátrico por uma rede de serviços territoriais de atenção psicossocial, essa abordagem ainda sofre 
resistência por setores ligados à indústria hospitalar. Dessa forma, são recorrentes as tentativas desse setor em inviabilizar o funcionamento dos serviços de atenção psicossocial com base comunitária, e reduzir o protagonismo dos usuários dos serviços e seus familiares no tratamento (RAZZOUK, 2013; AMORIM; SEVERO, 2019).

Na Rede de Atenção Psicossocial de Belo Horizonte, destacam-se os Centros de Convivência, definidos como espaços de sociabilidade, produção e intervenção, considerados fundamentais ao processo de desinstitucionalização. 0 Centro de Convivência apresenta como proposta, por meio de oficinas que favorecem relações de convívio, a sustentação das diferenças e a edificação de laços sociais, além de proporcionar a criação, a expressão e a produção de arte e o fortalecimento da cultura como uma possibilidade de resgate da cidadania das pessoas em sofrimento mental (SOARES; REINALDO, 2010). Os usuários dos serviços são pessoas com transtornos mentais graves que se encontram em tratamento na rede de saúde mental pública e privada do município (COORDENAÇÃO DE SAÚDE MENTAL, 2005).

A importância da alimentação para o bem-estar geral do indivíduo foi reconhecida juridicamente quando se incluiu o acesso a ela no rol dos direitos sociais na Constituição Brasileira, por meio da Emenda Constitucional no 64/2010, conforme descrito em seu artigo 6ㅇ: "são direitos sociais a educação, a saúde, a alimentação, o trabalho, a moradia, o lazer, a segurança, a previdência social, a proteção à maternidade $\mathrm{e}$ à infância, a assistência aos desamparados, na forma desta Constituição" (BRASIL, 2010a, p.1).

Nesse sentido, o Estado Brasileiro, ocupado com a construção de uma nova abordagem para atuar no combate à fome, à pobreza e na promoção da alimentação adequada e saudável, publicou a Lei 11.346/2006 - Lei Orgânica de Segurança Alimentar e Nutricional (BRASIL, 2006) e o Decreto 7.272/2010 - Política Nacional de Segurança Alimentar e Nutricional (BRASIL, 2010b). A Lei e o Decreto apresentam, entre as suas bases diretivas, o fortalecimento das ações de alimentação e nutrição no sistema de saúde. Embora a garantia jurídica não se reflita, necessariamente, em exercício de fato, num país com extremas desigualdades sociais e econômicas, como é o Brasil, os dispositivos jurídicos são mecanismos importantes para garantir direitos.

A Lei 11.346, de 15 de setembro de 2006, que criou o Sistema Nacional de Segurança Alimentar (SISAN), deu um passo além quando, desde a sua ementa, determina que a alimentação adequada é um direito humano (BRASIL, 2006). Ressaltam-se, em suas Disposições Gerais, um convite à participação da sociedade civil organizada na formulação de políticas, programas e ações visando assegurar esse direito; a promoção da saúde via práticas alimentares que respeitem, entre outras dimensões, a diversidade cultural e que sejam sustentáveis; e a importância da alimentação adequada considerada "direito fundamental do ser humano, inerente à dignidade da pessoa humana e 
indispensável à realização dos direitos consagrados na Constituição Federal”. Ainda, o art. 4ํㅡㄹ inciso III, abre, entre o público-alvo da promoção da saúde, da nutrição e da alimentação, a possibilidade de atenção especial a alguns segmentos: os "grupos populacionais específicos e populações em situação de vulnerabilidade social" (BRASIL, 2006).

A segurança alimentar e nutricional consiste na realização do direito ao acesso a alimentos de qualidade, em quantidade suficiente, sem comprometer outras necessidades essenciais. Pressupõe-se que seu alcance implique a convergência de políticas e programas de vários setores com capacidades para promover, na dimensão individual e coletiva, o acesso à alimentação adequada, requerendo um amplo processo de descentralização, territorialização e gestão social. Esse desafio de ofertar alimentação adequada a todos abarca uma série de políticas públicas (SANTOS; HENRIQUE, 2018).

Esse conjunto de políticas públicas possibilitou que o Brasil saísse, em 2014, do Mapa da Fome da Organização das Nações Unidas para Alimentação e Agricultura (FAO). O país foi citado como um caso de sucesso por ter reduzido de forma expressiva a fome, a desnutrição e a subalimentação nos últimos anos, com destaque para a governança de Segurança Alimentar e Nutricional (SAN) adotada (OPAS, 2017). Conforme o último Mapa da Fome da ONU, publicado em 2014, o Brasil diminuiu bruscamente o percentual de pessoas em situação de fome, alcançando quantitativo inferior a $5 \%$ da população com baixo consumo calórico. Pela primeira vez na história do Brasil, saímos do grupo de países considerados em grave situação de fome e extrema pobreza, para o conjunto das nações que mais investiram em ações de Segurança Alimentar e Nutricional, o que simbolizou o esforço do Estado brasileiro no compromisso de combater a fome (CRUZ, 2020).

Porém, em junho de 2017, a "Agenda 2030" publicou o relatório síntese que indicou o crescente aumento da pobreza no país e, consequentemente, o retorno expressivo da fome aos lares brasileiros. Segundo o documento, as causas desse retrocesso seriam tanto a recessão e a crise fiscal, que se instalou em 2015, quanto às medidas governamentais adotadas para a saída da crise, que incidiram indiretamente na Segurança Alimentar e Nutricional. Em novembro de 2018, a ONU publicou o relatório "Panorama da Segurança Alimentar e Nutricional na América Latina e Caribe" o qual apontou que a estimativa de brasileiros que sofriam com a escassez de alimentos chegava a 5 milhões, mesmo número em 2010 (CRUZ, 2020).

Além disso, durante a passagem do ano de 2019 para o de 2020, o mundo foi surpreendido com a transmissão do novo coronavírus, denominado SARS-CoV-2, causando uma doença até então desconhecida, a Covid-19. No início do ano de 2020, a Organização Mundial de Saúde (OMS) declarou à saúde pública internacional um alerta emergencial, de mais alto nível, de contaminação pelo novo coronavírus. Devido ao risco em larga escala de disseminação do vírus, foram necessárias ações estratégicas e 
coordenadas em curto tempo por parte dos governos, tendo em vista a mitigação dos impactos da contaminação. E, no mês de março, a Covid-19 foi caracterizada como uma pandemia pela OMS (CRODA et al., 2020). Assim, somando-se a conjuntura retrógrada no combate à fome no Brasil e as consequências da pandemia do novo coronavírus, a projeção dos estudos citados é que o cenário da fome se acentuará no país, arrastando milhares de pessoas à situação da extrema pobreza.

Na definição de "alimentação saudável" do Ministério da Saúde são considerados os aspectos nutricionais - um padrão alimentar que atenda às necessidades biológicas do indivíduo de acordo com sua faixa etária - e os socioculturais (BRASIL, 2003). No Guia Alimentar para a População Brasileira são apresentadas, basicamente, as seguintes condições para atingir essa alimentação, direito de todos os indivíduos: 1) Fazer de alimentos in natura ou minimamente processados a base da alimentação; 2) Utilizar óleos, gorduras, sal e açúcar em pequenas quantidades ao temperar e cozinhar alimentos e criar preparações culinárias; 3) Limitar o consumo de alimentos processados; 4) Evitar o consumo de alimentos ultraprocessados; 5) Comer com regularidade e atenção, em ambientes apropriados e, sempre que possível, com companhia; 6) Fazer compras em locais que ofertem variedades de alimentos in natura ou minimamente processados; 7) Desenvolver, exercitar e partilhar habilidades culinárias; 8) Planejar o uso do tempo para dar à alimentação o espaço que ela merece; 9) Dar preferência, quando fora de casa, a locais que servem refeições feitas na hora; 10) Ser crítico quanto a informações, orientações e mensagens sobre alimentação veiculadas em propagandas comerciais (BRASIL, 2014; BRASIL, 2021).

A Política Nacional de Alimentação e Nutrição possui como diretriz a promoção de práticas alimentares adequadas e saudáveis, compreendendo um conjunto de ações que objetivam proporcionar práticas alimentares nutricionalmente adequadas condizentes com os aspectos biológicos e socioculturais dos indivíduos e coletividades. A Educação Alimentar e Nutricional (EAN) integra essas ações em conjunto com a regulação de alimentos e incentivo à criação de ambientes promotores da alimentação saudável, como os centros de convivência (BRASIL, 2012a; BO0G, 2013; LANG, RIBAS, 2016). As ações da EAN baseiam-se em diferentes abordagens educacionais e pedagógicas que propiciam o diálogo e a reflexão sobre aspectos relacionados a alimentação e nutrição (SANTOS, 2005; BRASIL, 2012b).

0 projeto 'Oficina do Cuidado de si' foi criado em 2008 com o objetivo de desenvolver oficinas de promoção da saúde para usuários de um Centro de Convivência da Rede de Atenção Psicossocial (RAPS) do município de Belo Horizonte. Os Centros de Convivência são dispositivos de arte e cultura que fazem parte do rol de equipamentos terapêuticos que constituem a RAPS, esta, por conseguinte, é a rede substitutiva criada após a Reforma Psiquiátrica brasileira como estratégia política, social, de saúde e 
administrativa em oposição ao hospital psiquiátrico e suas ações de isolamento e institucionalização.

O projeto desenvolve ações por meio de oficinas, nas quais alunos da graduação, bolsistas de extensão dos cursos de Nutrição e Enfermagem, realizam atividades que, além de promover a saúde dos usuários do serviço, que são pessoas acometidas por transtornos mentais, promovem autonomia e autocuidado, viabilizando a reabilitação psicossocial para aqueles que apresentam dificuldades em gerir sua saúde.

Diante da insegurança alimentar e nutricional da atualidade na população em geral, observa-se que no campo da saúde mental essas fragilidades se dão de forma mais acentuada. Questões relacionadas a escolha, preparo e armazenamento dos alimentos foram descritas pelos usuários do Centro de Convivência, apontando para a necessidade de o projeto realizar oficinas específicas para abordar o tema alimentação e nutrição. Nesse sentido, 0 projeto de extensão 'Oficinas do cuidado de si' ampliou suas ações para atender a uma demanda, relacionada à alimentação, dos usuários do Centro de Convivência da Rede de Atenção Psicossocial da cidade de Belo Horizonte, Minas Gerais. Os cursos de graduação em Nutrição e Enfermagem da Universidade Federal de Minas Gerais passaram a planejar e desenvolver de forma coordenada o projeto de extensão "Educação Nutricional para portadores de sofrimento mental”, oferecendo, assim, outra possibilidade de intervenção e promoção da saúde, relacionada a alimentação e nutrição, à comunidade daquele Centro de Convivência.

As oficinas educativas são potentes ferramentas de promoção à alimentação saudável (CASTRO et al., 2007; MATTOS, ROCHA, RODRIGUES, 2018; ROCHA et al., 2020), e quando aplicadas à saúde mental são uma estratégia clínica e política no processo de desinstitucionalização da loucura e reinserção psicossocial da pessoa em sofrimento mental, além de permitir o enlaçamento do sujeito ao liame social por meio da construção do vínculo, promovendo a reinserção social do sujeito e a reabilitação psicossocial da pessoa (DIAS, 2018).

É importante verificar os impactos das oficinas educativas em relação à alimentação e à nutrição das pessoas em transtorno psiquiátrico. Além disso, os resultados desta pesquisa de avaliação possibilitarão melhorias no projeto de extensão. Assim, o objetivo deste estudo foi avaliar a efetividade das oficinas educativas de nutrição realizadas em um Centro de Convivência para pessoas com transtorno psiquiátrico no município de Belo Horizonte, Minas Gerais. 


\section{PROJETO DE EXTENSÃO EM NUTRIÇÃO E SAÚDE MENTAL}

A educação como prática transformadora e a aprendizagem significativa são premissas da educação permanente. Segundo Paulo Freire, a dialogicidade indica a dimensão do caráter inacabado dos homens e a realidade em constante mudança, com necessidade de uma educação como atividade continuamente refeita, a partir da leitura crítica da realidade, para a transformação da mesma (CAMPOS, SENA, SILVA, 2017).

Neste contexto, o projeto de extensão busca o diálogo e a troca de saberes entre os atores envolvidos nas atividades - os professores, os alunos e pessoas com transtorno psiquiátrico. 0 objetivo é que possa ser produzido em conjunto educativas um novo conhecimento, que contribua para a superação da desigualdade e da exclusão social e para a construção de uma sociedade mais justa, ética e democrática (FORPROEX, 2012).

0 projeto de extensão busca a integração dos estudantes e professores de Nutrição e Enfermagem com os colaboradores do Centro de Convivência por meio de reuniões semanais em que se abordam o plano de trabalho, as atividades desenvolvidas, os resultados alcançados, as dificuldades e as propostas de seguimento desta ação de extensão. Os temas das oficinas são definidos após consulta prévia com os seus participantes e com a equipe do projeto, pois a proposta do projeto prevê uma relação de parceria e de diálogo, na qual todos os sujeitos são participantes ativos no processo, isto é, portadores de saberes, que falam, ouvem, compartilham opiniões, encontram semelhanças, divergem, ressignificam conceitos e se modificam a partir dessa relação (CERVATO-MANCUSO; VINCHA; SANTIAGO, 2016). Nas reuniões semanais, também é definida a técnica lúdica a ser utilizada nas oficinas. Vale salientar que as reuniões de acompanhamento do projeto também permitiam uma reflexão sobre a prática contribuindo para adequá-la à realidade vivenciada.

Os estudantes participam da definição dos temas, técnicas lúdicas e materiais didáticos utilizados nas oficinas educativas dentro da perspectiva da promoção de modos de vida saudáveis. Dessa forma, eles podem aplicar o conhecimento aprendido na graduação e, a partir do estudo da temática de cada oficina com a leitura dos materiais complementares, como artigos científicos e livros, contribuir para a elaboração de materiais didáticos e execução da oficina educativa. As técnicas lúdicas são utilizadas para facilitar a adesão e a mobilização do sujeito de forma integral (MONTEIRO et al., 2012).

As oficinas educativas de nutrição, analisadas neste artigo, foram realizadas semanalmente com diversos temas relacionados à saúde, alimentação e nutrição, com utilização de técnicas lúdico-pedagógicas. Participavam, em média, seis usuários, de forma contínua, e dois de modo não contínuo. Na realização de oficinas para usuários dos serviços de saúde mental, a participação se dá de forma flutuante, em alguns casos devido 
a ansiedade e dificuldade para permanecer por muito tempo no mesmo ambiente, outras por dificuldades de atenção e manutenção da atenção, comuns aos transtornos mentais graves. A duração de cada oficina educativa era de 40 minutos.

Para divulgar as oficinas dentro do serviço, são confeccionados cartazes com informações sobre o dia, horário e a temática a ser abordada. Os profissionais do serviço e participantes também divulgam para os outros usuários do Centro de Convivência.

Os temas abordados nas oficinas educativas entre 2008 e 2016 foram:

- Alimentação e nutrição: Água, leite e derivados; Cor e alimentação; Alimentos diet e light e Doenças do metabolismo.

- Produção dos alimentos e agrotóxicos.

- Alimentos específicos: Chás e seus benefícios; Chocolate; Frutas; Ovos; Refrigerantes; Sucos naturais, em polpa, industrializados.

- Higienização e conservação dos alimentos: Armazenamento de alimentos; Organização da geladeira e despensa; Contaminação dos alimentos por microrganismos;

- Comportamentos e reflexos na saúde: Alimentação e nutrição; Alcoolismo e nutrição; Cigarro x nutrição; Estresse e alimentação; A importância da prática de exercícios físicos;

- Escolhas alimentares: Planejamento da alimentação; Alimentação fora de casa; Alimentos e humor; Ácidos graxos essenciais; Digestão, fibras alimentares, gordura trans e pirâmide alimentar.

Foram elaborados e utilizados nas oficinas educativas: folders; cultivo de horta; jogos adaptados, tais como bingo, cartas, memória; jogos criados pelos estudantes; pirâmides alimentares; dinâmicas de grupo diversas; e filmes na abordagem desses temas. A produção do material é realizada pelos extensionistas e busca utilizar materiais simples, linguagem acessível, possibilidade de interação e estratégia didático-pedagógica adequada ao tema abordado.

No campo da saúde mental, as oficinas educativas são utilizadas de forma corrente para ações de promoção da saúde e prevenção de agravos. A organização das oficinas passa pela escolha do tema, organização e pesquisa de fontes, sendo especial o cuidado com a linguagem e adaptação de conceitos e informações complexos para a linguagem corrente. Além disso, é necessário considerar que os usuários dos serviços de saúde mental são pessoas que, em sua maioria, têm diagnósticos de transtornos mentais graves e sua sintomatologia deve ser considerada no momento da abordagem e da construção do material educativo. Questões relacionadas ao tempo, à linguagem, à imagem, e à interação devem ser consideradas (SILVEIRA, SOARES, REINALDO, 2010). 


\section{METODOLOGIA}

O presente estudo trata de uma avaliação da efetividade do projeto de extensão "Educação nutricional para portadores de sofrimento mental" registrado no Sistema de Informações de Extensão UFMG (SIEX) cujas atividades são baseadas na realização de oficinas educativas de nutrição realizadas em um Centro de Convivência com atividades específicas para indivíduos com transtornos mentais que estão em acompanhamento na Rede de Atenção Psicossocial de Belo Horizonte - MG.

Trata-se da análise de uma ação específica, portanto o presente estudo pode ser definido como sendo um estudo de caso. Pereira et al. (2018) considera que essa metodologia investiga fenômenos individuais ou processos sociais, e segundo Yin (2014), esse é um procedimento que presume detalhamento das relações entre indivíduos e organizações, bem como as trocas que ocorrem com o meio em que estão inseridos.

0 instrumento de coleta de dados foi um roteiro de entrevista estruturada com questões que buscaram permitir a percepção dos indivíduos a respeito de uma alimentação saudável a partir das oficinas, e a aplicabilidade no cotidiano. Os sujeitos da pesquisa foram os usuários do Centro de Convivência que participaram de forma contínua das oficinas educativas de nutrição e a gerente do serviço. As entrevistas foram realizadas no serviço, em ambiente reservado, com duração de 40 a 50 minutos. Todos os participantes ( 6 pessoas) da oficina foram convidados a participar da avaliação da atividade de extensão, porém apenas quatro concordaram, os demais (duas pessoas) se recusaram a colaborar com a avaliação.

Os colaboradores da avaliação foram identificados com as letras A, B, C e D, de forma a preservar a identidade dos participantes. O período de coleta das informações ocorreu entre outubro e novembro de 2016, no Centro de Convivência, por meio de entrevista gravada. As entrevistas tiveram duração entre 40 e 50 minutos. As oficinas educativas realizadas no período de 2008 a 2016 foram quantificadas e tabuladas para caracterização do projeto em relação à sua produção.

As falas dos participantes foram gravadas e transcritas para posterior análise de conteúdo, o que permitiu avaliar se a ação de extensão obteve êxito tanto no que se refere à aquisição de conhecimento e conceitos sobre saúde, nutrição e alimentação quanto no que tange à multiplicação do conhecimento adquirido (BARDIN, 2011).

A fim de subsidiar as análises e reflexões dos resultados obtidos, foram elaborados alguns pressupostos norteadores em relação às oficinas educativas de nutrição: a) As oficinas de educativas de nutrição contribuíram para a melhoria da qualidade da alimentação dos indivíduos em transtorno psiquiátrico? b) As oficinas 
educativas proporcionaram mudanças no comportamento alimentar em seus participantes?

\section{RESULTADOS E DISCUSSÃO}

O desenvolvimento das oficinas educativas reafirmou a relevância, a essencialidade e a eficácia dessa metodologia na abordagem às pessoas com transtorno psiquiátrico, visto que permite uma real assunção da posição ativa na (re)construção de saberes e de reflexões acerca do próprio bem-estar.

De 2008 a 2016, foram realizadas 97 oficinas educativas, com participação total de 582 pessoas com transtornos psiquiátricos nesse período. A presença dos usuários do serviço nas oficinas não foi constante, alternando em relação ao número de participantes ao longo do ano. Participaram, em média, de forma contínua, seis usuários por semana, e dois de modo não contínuo. Cabe citar que o Centro de Convivência oferece um leque de oficinas ligadas às artes (música, teatro, expressão corporal), ao artesanato (bordado, pintura em tecido, escultura, costura) e à saúde (educação física, enfermagem, nutrição). O usuário do Centro de Convivência pode se inscrever em até duas oficinas.

Foram entrevistados quatro participantes das oficinas educativas de nutrição de forma contínua: três homens e uma mulher, com idade média de 50 anos, solteiros à época da coleta de dados. Do ponto de vista do trabalho, dois relataram estar aposentados; um alegou ser trabalhador informal; e um afirmou estar sem ocupação. Em relação à escolaridade, dois indivíduos disseram ter o ensino médio completo; um disse que tinha o ensino fundamental completo e o último não soube informar. Os outros dois participantes de forma contínua das oficinas educativas não quiseram participar do estudo.

Em relação às questões de saúde, havia, no grupo entrevistado, quadros de alcoolismo, depressão e psicose. 0 "aprender sobre saúde" e a "melhora do humor" foram citados como razões que os mantiveram nas oficinas de educação nutricional.

A alimentação adequada e saudável é um direito humano básico que envolve a garantia ao acesso permanente e regular, de forma socialmente justa, a uma prática alimentar adequada aos aspectos biológicos e sociais do indivíduo e que deve: estar em acordo com as necessidades alimentares especiais; ser referenciada pela cultura alimentar e pelas dimensões de gênero, raça e etnia; ser acessível do ponto de vista físico e financeiro; ser harmônica em quantidade e qualidade, atendendo aos princípios da variedade, equilíbrio, moderação e prazer; e ser baseada em práticas produtivas adequadas e sustentáveis (BRASIL, 2014). 
Os fatores que constroem e modificam o comportamento alimentar são diversos. Influências externas e internas estão intimamente ligadas com a relação entre o indivíduo e a forma como ele se alimenta (TORAL; SLATER, 2007). As influências internas e externas podem conduzir a um comportamento alimentar inadequado e consequentemente ao excesso de peso, fator capaz de desencadear o desenvolvimento de doenças crônicas não transmissíveis (DCNTs) (ALVARENGA et al., 2016). Para prevenir as DCNTs é necessário adotar um estilo de vida saudável que inclua um comportamento alimentar adequado (BARBOSA et al., 2016).

Na entrevista os usuários compartilharam opiniões e experiências em relação a uma alimentação saudável e a mudanças no seu comportamento alimentar a partir das oficinas educativas, como mostram os relatos:

Uma alimentação saudável... quando chega em casa, lavar as frutas, colocar dentro da geladeira [...] é você comer moderadamente, saber comer direito, fazer o seu o seu cardápio. (PARTICIPANTE A).

Ah, uma alimentação com bastante verdura, não é? (PARTICIPANTE B).

Aquela que é balanceada, sabe? Que não tem uns petiscos. Porque, às vezes, a gente come muito sem ser balanceada. Mistura muita coisa. Às vezes, as coisas que não têm nada a ver, a gente está comendo. É essa que eu acho que é a comida saudável. (PARTICIPANTE C).

Ah, é comer na hora certa; de três em três horas e ... e banho... três vezes ao dia [....] (PARTICIPANTE D).

A fim de verificar a compreensão dos usuários sobre o significado de “alimentação saudável”, e tomando-se como referência o almoço, os sujeitos assim se manifestaram:

Eu colocaria arroz, feijão, macarrão, salada... carne moída... e um copo de leite. (PARTICIPANTE A).

Um prato saudável pode ser arroz, feijão e... carne e... um pouco de verdura. (PARTICIPANTE B).

Eu colocaria uma colher de arroz, uma de feijão, salada, um bife de frango [...] (D).

Dessa forma, observou-se, a partir dos exemplos citados que os usuários assimilaram o conceito sobre "alimentação saudável" na composição de uma refeição. Ainda explorando o aprendizado sobre o conceito de "alimentação saudável", os usuários foram questionados sobre a contribuição das oficinas educativas de nutrição na sua alimentação. Os relatos encontram-se descritos abaixo.

Tem me ajudado muito quando compro as coisas no supermercado, eu olho muito... eu olho o preço, eu olho a qualidade, eu olho a quantidade que eu vou comer [...] (PARTICIPANTE A).

Tem sim. Estou gostando bastante.... A segunda oficina falou do que que eu devo comer, alimentar para fazer bem. (PARTICIPANTE B). 
Ajuda muito. Ajuda porque eu já fico podendo orientar até a minha família, sabe? Porque, às vezes, eles ficam fazendo umas coisas que, às vezes, não é legal. Porque eu como no restaurante tipo popular e lá fica uma nut [...] como que chama... vocês? É uma pessoa que faz a nutrição lá da comida dos restaurantes. Às vezes, tem outros restaurantes que faz comida caseira, mas não tem uma pessoa que faz a comida balanceada. Orientando a gente. (PARTICIPANTE C).

Tem. Diminui para mim a comida... eu estava pesando muito, agora estou pesando menos... (PARTICIPANTE D).

Eu comia muita carne gordurosa... comia muito... eu exagerava muito no biscoito. No biscoito recheado... no... macarrão instantâneo. (PARTICIPANTE A).

Os participantes, ao serem questionados sobre as mudanças em seus hábitos alimentares, como, por exemplo, o consumo de "macarrão instantâneo", sal, suco industrializado e frituras (gordura), relataram:

Não consumo mais! (PARTICIPANTE A).

Diminuí... Ah, diminuí no sal [...] E o suco [...] 0 suco eu também mudei o suco. Estou tomando mais suco natural. Antes, eu comprava de pozinho... agora tomo mais natural [...] está me ajudando bastante na minha alimentação. Antes eu não me alimentava direito. Agora que eu passei a fazer a oficina, eu passei a me alimentar melhor. (PARTICIPANTE B).

A questão é que eu não sabia o que fazia mal para minha saúde, sabe? Aí eu comecei a comer outras coisas que eu não comia [...]. Agora eu evito comer muita gordura. (PARTICIPANTE C).

Era suco de caixinha que eu tomava [....] Agora é suco natural! A nutricionista, [cita um nome] passou para mim [...] ela até me deu uma revista: sucos que curam [...]. (PARTICIPANTE D).

As mudanças no consumo de alimentos pelos usuários do Centro de Convivência puderam ser observadas a partir dos relatos que descrevem as compras no supermercado e a aplicação de conceitos de uma alimentação saudável (redução do consumo de sal, gordura, alimentos processados e ultraprocessados, e aumento do consumo de vegetais e folhosos), e em seu comportamento durante as oficinas culinárias. De acordo com os próprios usuários, as oficinas educativas têm auxiliado em suas escolhas alimentares, melhorando o seu hábito alimentar e a qualidade de vida, mas como todo processo educativo, este ainda é um processo em construção, como mostram os relatos a seguir.

Então, você sentiu mesmo uma mudança na sua alimentação? (Entrevistadora). Senti! Senti, sim! Apesar de que não dá para seguir sempre, sabe? Porque às vezes eu não como em casa, aí lá [em restaurantes] como diferente. Não dá para ficar separando [...]. (PARTICIPANTE C).

Em relação às mudanças e informações que os usuários assimilaram a partir das oficinas educativas, observa-se a regularidade na alimentação, a introdução de alimentos que não eram consumidos anteriormente (como as verduras), a preferência por alimentos naturais, desenvolver habilidades culinárias, não ter grandes intervalos entre as refeições, e a opção por modos de preparação mais saudáveis. Esses são alguns dos Dez Passos para 
uma Alimentação Adequada e Saudável, conforme descrito no Guia Alimentar (BRASIL, 2014). Abaixo, destacamos trechos dos relatos dos usuários.

E, depois das oficinas, você diz que 'está' perdendo peso: é porque 'tá' comendo menos, ou comendo de três em três horas [...]? (Entrevistadora).

Comendo de três em três horas [...] (PARTICIPANTE D).

É você saber cozinhar as coisas, saber alimentar, saber o horário correto, saber como comer moderadamente [...] (PARTICIPANTE A).

E dessas orientações/dicas que você citou, quais você usa mais? (Entrevistadora).

Comer saudável. Alimentar bem [...] antes eu não comia verdura, agora estou comendo bastante verdura [....] o espinafre, alface, cenoura, abóbora também [....] (PARTICIPANTE B).

É que a gente tem que olhar coisas mais naturais. Comer a coisa mais natural possível. (PARTICIPANTE C).

É [...] aquele negócio de cereal [...] que pode comer cereais... é... ferro [...] vitamina [...] vitamina não, é saladas [...]. Não pode comer coisa gordurosa: sorvete, doces, bolo [...]. Comer cenoura para nascer os cabelos [...] ovo cozido [...] porque ele é melhor do que ele frito [...]. Igual eu faço frango só com [....] eu douro a cebola e deixo cozinhar só no bafo da cebola. É [...] verdura, verdura eu ponho para cozinhar com a água [...] e pode pôr na carne ou no frango [...] aí, põe a água da verdura [...] aproveita a água [...] da verdura [...] (PARTICIPANTE D).

No momento em que a entrevistadora agradecia a participação do entrevistado e se despedia, um elogio espontâneo foi feito, mostrando a importância da presença da Universidade nesse espaço.

Obrigada! Você gosta, então, da oficina de nutrição?" (Entrevistadora).

Gosto! Bastante! Porque aprende a comer moderadamente, saudável, para eu não ter na minha fase da velhice uma doença [...] porque alimento também causa doença [...]. Para mim ter uma velhice saudável. (PARTICIPANTE A).

Observou-se, sobre alimentação saudável, uma apropriação adequada da necessidade de vegetais, verduras e frutas. Os exemplos de refeição quanto aos Grupos de Alimentos foram: arroz, feijão, carne moída, carne e frango e verduras/salada. A questão da quantidade apareceu na resposta da entrevistada B (que na definição de alimentação saudável, refere-se a "um pouco de verdura"). 0 indivíduo A relatou, em outro momento da entrevista, a inclusão de "um copo de leite" no almoço como um hábito familiar, cultural. Embora todos os entrevistados tenham-se mostrado disponíveis, em alguns momentos, houve limitação aparente no desenvolvimento das ideias, característica associada a dificuldades no fluxo e concatenação do pensamento.

A proposta de oficinas educativas de nutrição aos pessoas com transtorno psiquiátrico surgiu do interesse verbalizado pelos usuários do Centro de Convivência em oficinas de Enfermagem, em 2008. Articular as preocupações e saberes dos participantes 
em direção ao que seriam conhecimentos importantes, do ponto de vista da alimentação saudável, é o desafio de cada uma das oficinas de Nutrição.

Na visão da gerente do Centro de Convivência, baseado nos relatos dos usuários sobre a sua alimentação antes do início do projeto de extensão, há, inegavelmente, um espaço a ser ocupado pela Nutrição junto ao seu público e o desafio maior é a apropriação, por parte deste, do autocuidado, conforme o relato a seguir:

Eu acho que esse projeto é importante para o Centro de Convivência. A gente tem várias questões [...] algumas questões com o usuário. Acho que eles comem muito mal, no sentido de que às vezes, não é nem questão de dinheiro, mas uma questão do mais fácil. Algumas medicações têm efeito no corpo, tem medicação que engorda, então, é bacana a gente poder desenvolver nos usuários alguns hábitos mais saudáveis. (Gerente do Centro de Convivência).

É interessante observar que, nas definições citadas pelos entrevistados para "alimentação saudável”, foram destacados vários elementos do Guia Alimentar (BRASIL, 2014): cuidados com a higienização e armazenamento; alimentos que deveriam compôla; periodicidade do ato de alimentar-se e modo; redução no consumo de alimentos processados e ultraprocessados; aumento do consumo de alimentos in natura; e redução no consumo de óleo e sal. A compreensão da necessidade de adequação individual da alimentação também foi sugerida, como se pode conferir nas respostas dos participantes das oficinas.

As oficinas são consideradas como um espaço de alcance de novos conhecimentos e habilidades, que podem ser utilizados no cotidiano dos usuários do Centros de Atenção Psicossocial. Elas visam à melhoria na qualidade de vida dos usuários do serviço, incentivadas pela abordagem multidisciplinar, tomando como norte a visão de que os profissionais atuam contribuindo para a reabilitação psicossocial dos usuários.

Resultados semelhantes aos obtidos no projeto em tela foram encontrados em um estudo realizado em Centros de Atenção Psicossocial, com levantamento de dados de artigos científicos entre 2007 e 2017. Os resultados demonstram as oficinas terapêuticas como atividades que contribuem para a efetivação da mudança social acerca da loucura e para a inclusão de pessoas com transtornos mentais no cotidiano familiar, na comunidade e do próprio agir do sujeito (IBIAPINA et al., 2019). Pagassini e colaboradores (2015) realizaram oficinas educativas em um CAPS e expressam que oficinas terapêuticas são bons recursos de tratamento, uma vez que estimulam a capacidade de produção, integração e convivência em grupo (PAGASSINI et al., 2015).

Em outros estudos as oficinas educativas também foram utilizadas como ferramentas metodológicas e obtiveram impactos positivos no público-alvo semelhantes a esta atividade extensionista. Ibiapina e colaboradores (2017), ao analisarem o impacto das oficinas terapêuticas e as mudanças sociais em pessoas com transtornos mentais sob 
a ótica da vivência dos trabalhadores de um Centro de Atenção Psicossocial, observaram que a utilização das oficinas terapêuticas contribuiu para a efetivação da mudança social acerca da doença mental e para inclusão social de pessoas com transtornos psíquicos no cotidiano familiar, na comunidade, incentivadas pela abordagem multidisciplinar (IBIAPINA et al., 2017). Também foi possível avaliar a percepção dos familiares acerca da importância do tratamento dentro do CAPS, bem como pontuando estas oficinas como atividades primordiais para a reinserção, reabilitação e resgate da cidadania deste indivíduo portador de transtorno psíquico na sociedade (CRUZ et al., 2016).

A partir dos relatos, na percepção dos entrevistados, as oficinas auxiliaram na compra de alimentos (preço, qualidade, estabelecimento de quantidades); na escolha; perda de peso; e no posicionamento diante da família, que passa a ser orientada pelo sujeito portador de transtorno psiquiátrico.

Algumas mudanças relatadas pelos sujeitos da pesquisa, em relação à própria alimentação após sua participação nas oficinas, foram o aprendizado da moderação no consumo de alimentos menos saudáveis (particularmente gorduras, frituras, sal), a substituição de alimentos industrializados por alimentos mais saudáveis no dia a dia, maior atenção à própria saúde, e a perda de peso. As oficinas, além de contribuírem para a desconstrução de alguns hábitos alimentares não adequados, podem reforçar saberes prévios, como a importância da higienização dos alimentos, conforme pontuado por um dos entrevistados.

As oficinas de extensão também possibilitam que os usuários do Centro de Convivência compartilhem os seus saberes prévios relacionados principalmente ao cultivo de horta e preparações culinárias típicas de Minas Gerais, proporcionando, assim, a interação dialógica entre a Universidade e o setor social.

Num estudo realizado por Pereira e Palma (2018), os usuários das oficinas terapêuticas, assim como os usuários das oficinas educativas de nutrição, as consideram como espaços onde seus sentimentos eram qualificados e suas relações humanizadas. Mattos, Rocha e Rodrigues (2018) relatam a experiência de oficinas educativas de horticultura como ferramenta de cuidado com as pessoas com transtorno psiquiátrico em um Centro de Atenção Psicossocial Álcool e outras Drogas (CAPS) em São Leopoldo. Observou-se que as atividades permitiram diálogos sobre segurança alimentar e nutricional e atividades de educação alimentar e nutricional da mesma forma que as atividades de extensão deste projeto.

A Educação Alimentar e Nutricional (EAN) é um objeto de ação multiprofissional, intersetorial e transdisciplinar, em que o conhecimento e o aprendizado, contínuo e permanente, propõem-se a desenvolver a autonomia e a voluntariedade ante os hábitos alimentares saudáveis, fazendo o uso de recursos e abordagens educacionais ativas e problematizadoras (SANTOS, 2019; FRANÇA; CARVALHO, 2017; CERVATO-MANCUSO, 
VINCHA, SANTIAGO, 2016). A EAN protagoniza importante eixo na promoção de hábitos alimentares saudáveis, sendo uma estratégia indispensável dentro das políticas públicas em alimentação e nutrição (FRANÇA; CARVALHO, 2017). Portanto, refletir sobre questões práticas do seu cotidiano, aprender a escolher alimentos, a preparar algumas refeições, talvez até a cultivar alguns alimentos, são formas de chamar o sujeito para a ação. As atividades podem ser diversificadas, a linguagem deve ser acessível, respeitosa, não infantilizada.

O projeto de extensão "Educação nutricional para portadores de sofrimento mental", por meio das oficinas de educação nutricional, tem contribuído para a promoção de hábitos de vida saudáveis para os usuários do Centro de Convivência com o objetivo de melhoria de sua qualidade de vida, baseada no aprendizado de novos saberes e numa relação dialógica. 0 estudo demonstrou a importância e a efetividade das oficinas educativas para a promoção da saúde e como ação de prevenção de doenças crônicas nãotransmissíveis para as pessoas com transtorno psiquiátrico.

\section{CONCLUSÕES}

0 presente artigo relatou a experiência de ensino-aprendizagem desenvolvido com pessoas portadoras de transtorno psiquiátrico e avaliou a efetividade do projeto de extensão intitulado "Educação nutricional para portadores de sofrimento mental", indicando efetivas melhorias na promoção da saúde e práticas alimentares saudáveis das pessoas com transtornos mentais em um Centro de Convivência em Belo Horizonte-MG. Os participantes se apropriaram de conhecimentos relacionados à saúde, à nutrição e à alimentação com promoção de modos de vida saudáveis. As intervenções propostas por meio das oficinas educativas demonstraram grande potencial na construção do conhecimento e na adoção de hábitos de vida saudáveis pelas pessoas com transtorno psiquiátrico.

O projeto também proporcionou aos estudantes envolvidos a ampliação de seus conhecimentos sobre o tema "saúde mental", ainda pouco explorado no campo da Nutrição, a participação em uma equipe multiprofissional na área da saúde, além de diversificar as possibilidades de atuação profissional. Além disso, os estudantes também puderam se apropriar de ferramentas, metodologias e conhecimentos compartilhados durante as disciplinas e capacitações, tornando efetiva a prática dos conceitos teóricos vistos e discutidos em sala de aula.

O Centro de Convivência é um espaço importante para ações de Educação em Saúde dentro de uma abordagem de acompanhamento multidisciplinar, onde são realizadas, entre outras atividades, as oficinas educativas de nutrição. Nesse ambiente, 
pôde-se observar que as oficinas educativas de nutrição foram um instrumento para a recuperação e manutenção de hábitos alimentares saudáveis, atuando na prevenção de doenças e na melhoria das condições de saúde e qualidade de vida dos usuários dos Centros de Convivência. As oficinas educativas de nutrição para pessoas com transtorno psiquiátrico são uma nova possibilidade da promoção à saúde no contexto dos Centros de Convivência e, por isso, faz-se necessária a ampliação do seu estudo e aplicação nesses ambientes, em virtude de seu potencial de protagonismo, e melhoria da qualidade de vida dos usuários.

Observa-se, a partir do relato dos participantes do estudo, o interesse sobre assuntos relacionados à alimentação e à nutrição, e o impacto da educação nutricional na promoção da saúde como uma estratégia fundamental para o enfrentamento dos problemas do processo saúde-doença-cuidado. 0 desenvolvimento das oficinas demonstrou auxiliar o resgate da cidadania ao valorizar as experiências dos participantes e sua possibilidade de aprendizagem. Na perspectiva dos sujeitos entrevistados, as oficinas de educação nutricional contribuíram para a melhoria de sua alimentação com reflexos em sua saúde.

\section{REFERÊNCIAS}

ALVARENGA, Marlene; FIGUEIREDO, Manoela; TIMERMAN, Fernanda; ANTONACCIO, Cynthia. Nutrição Comportamental. Barueri: Manole, 2016.

AMORIM, Ana Karenina de Melo Arraes; SEVERO, Ana Kalliny de Sousa. Saúde mental, cultura e arte: discutindo a reinserção social de usuários da rede de atenção psicossocial. Gerais: Revista Interinstitucional Psicologia, Belo Horizonte, v. 12, n. 2, p. 282-299, jul./dez. 2019.

BARBOSA, Lídia Bezerra; VASCONCELOS, Sandra Mary Lima; CORREIA, Lourani Oliveira dos Santos; FERREIRA, Raphaela Costa. Estudos de avaliação do conhecimento nutricional de adultos: uma revisão sistemática. Ciência \& Saúde Coletiva, Rio de Janeiro, v. 21, n. 2, p. 449-462, fev. 2016.

BARDIN, Laurence. Análise de conteúdo. Lisboa: Edições 70, 2011.

B00G, Maria Cristina Faber. Iniciando um trabalho em educação alimentar e nutricional: abrangências. In: B00G, Maria Cristina Faber. Educação em Nutrição: integrando experiência. Campinas: Komedi, 2013.

BRASIL. Decreto no 7.272, de 25 de agosto de 2010. Regulamenta a Lei no 11.346, de 15 de setembro de 2006, que cria o Sistema Nacional de Segurança Alimentar e Nutricional - SISAN com vistas a assegurar o direito humano à alimentação adequada, institui a Política Nacional de Segurança Alimentar e Nutricional - PNSAN, estabelece os parâmetros para a elaboração do Plano Nacional de Segurança Alimentar e Nutricional, e dá outras providências. Diário Oficial da União, Poder Executivo, Brasília, DF, 26 ago. 2010a. Seção 1, p. 6. Acesso em 10 Out de 2020. 
BRASIL. Emenda Constitucional no 64, de 4 de fevereiro de 2010. Altera o artigo 6으 da Constituição Federal para introduzir a alimentação como direito social. 2010b.

BRASIL. Marco de referência de educação alimentar e nutricional para as políticas públicas. Brasília: Ministério do Desenvolvimento Social, 2012. Disponível em: https://www.cfn.org.br/wp-content/uploads/2017/03/marco_EAN.pdf. Acesso em: 25 Maio 2020.

BRASIL. Guia alimentar para a população brasileira: promovendo a alimentação saudável. Brasília: Ministério da Saúde, 2014. Disponível em:

https://bvsms.saude.gov.br/bvs/publicacoes/guia_alimentar_populacao_brasileira_2ed. pdf . Acesso em: 15 Set 2019.

BRASIL. Protocolos de Uso do Guia Alimentar para a População Brasileira na Orientação Alimentar: Bases Teóricas E Metodológicas e Protocolo para a População Adulta. Brasília: Ministério da Saúde e Universidade de São Paulo, 2021. Disponível em: http://bvsms.saude.gov.br/bvs/publicacoes/protocolos_guia_alimentar_fasciculo1.pdf. Acesso em 25 Maio 2021.

BRASIL. Política Nacional de Alimentação e Nutrição. Brasília: Ministério da Saúde, 2012a. Disponível em:

https://bvsms.saude.gov.br/bvs/publicacoes/politica_nacional_alimentacao_nutricao.p df Acesso em: 20 Abril 2019.

BRASIL. Lei no 11.346, de 15 de setembro de 2006. Cria o Sistema Nacional de Segurança Alimentar e Nutricional - SISAN com vistas em assegurar o direito humano à alimentação adequada e dá outras providências. 2006. Disponível em:

http://www.planalto.gov.br/ccivil_03/_ato2004-2006/2006/lei/l11346.htm. Acesso em 26 Maio 2019.

CAMPOS, Kátia Ferreira Costa; SENA, Roseni Rosângela de; SILVA, Kênia Lara. Educação permanente nos serviços de saúde. Escola Anna Nery, Rio de Janeiro, v. 21, n. 4, e20160317. Disponível em: https://doi.org/10.1590/2177-9465-EAN-2016-0317. Acesso em: 13 Set 2021.

CASTRO, Inês Rugani Ribeiro et al. A culinária na promoção da alimentação saudável: delineamento e experimentação de método educativo dirigido a adolescentes e a profissionais das redes de saúde e de educação. Revista de Nutrição, Campinas, v. 20, n. 6, p. 571-588, nov./dez. 2007. Disponível em: https://doi.org/10.1590/S141552732007000600001. Acesso em: 13 Out 2018.

CERVATO-MANCUSO, Ana Maria; VINCHA, Kellem Regina Rosendo; SANTIAGO, Débora Aparecida. Educação alimentar e nutricional como prática de intervenção: reflexão e possibilidades de fortalecimento. Physis: Revista de Saúde Coletiva, Rio de Janeiro, v. 26, n. 1, p. 225-249, 2016. Disponível em: https://doi.org/10.1590/S010373312016000100013. Acesso em: 10 Out 2018.

COORDENAÇÃO DE SAÚDE MENTAL/SMSA/SUS-BH. Documento. Belo Horizonte; 2005 (Mimeo).

CRODA, Júlio et al. COVID-19 no Brasil: vantagens de um sistema único de saúde socializado e preparação para contenção de casos. Revista da Sociedade Brasileira de Medicina Tropical, Uberaba, v. 53, p. 1-6, 2020. Disponível em: https://doi.org/10.1590/0037-8682-0167-2020 . Acesso em: 10 Março 2021. 
CRUZ, Marta Pereira da; MONTEIRO, Claudete Ferreira de Souza; IBIAPINA, Aline Raquel de Sousa. Oficinas terapêuticas em saúde mental como instrumento de reabilitação psicossocial: percepção dos familiares. Revista de Enfermagem UFPE, Recife, v. 10, n. 11, p. 3996-4002, 2016.

CRUZ, Samyra Rodrigues da. Uma análise sobre o cenário da fome no brasil em tempos de pandemia do covid-19. Pensata, São Paulo, v. 9, n. 2, p. 1-15, nov. 2020. Disponível em: https://doi.org/10.34024/pensata.2020.v9.11104 . Acesso em: 10 março 2021.

DIAS, Janiele Daniane da Silva. Oficinas terapêuticas como estratégia para reinserção psicossocial e produção de vínculo. Pretextos: Revista Graduação de Psicologia PUC Minas, Belo Horizonte, v. 3, n. 5, p. 129-145, mar. 2018. Disponível em: http://periodicos.pucminas.br/index.php/pretextos/article/view/15933 . Acesso em: 10 Out 2020.

FRANÇA, Camila de Jesus; CARVALHO, Vivian Carla Honorato dos Santos. Estratégias de educação alimentar e nutricional na Atenção Primária à Saúde: uma revisão de literatura. Saúde em Debate, Rio de Janeiro, v. 41, n. 114, p. 932-948, jul./set. 2017. Disponível em: https://doi.org/10.1590/0103-1104201711421 . Acesso em: 10 Out 2020.

FÓRUM DE PRÓ-REITORES DE EXTENSÃO DAS INSTITUIÇÕES PÚBLICAS DE EDUCAÇÃO SUPERIOR BRASILEIRAS - FORPROEX. Política nacional de extensão universitária.

Belo Horizonte: ed. UFMG, 2012. Disponível em: https://www.ufmg.br/proex/renex/images/documentos/2012-07-13-PoliticaNacional-de-Extensao.pdf Acesso em: 13 Set 2021.

IBIAPINA, Aline Raquel de Sousa et al. Oficinas Terapêuticas e as mudanças sociais em portadores de transtorno mental. Escola Anna Nery, Rio de Janeiro, v. 21, n. 3, p. 1-8, 2017. Disponível em: https://doi.org/10.1590/2177-9465-ean-2016-0375. Acesso em: 10 Out 2020.

IBIAPINA, Aline Raquel de Sousa et al. Oficinas terapêuticas em Centro de Atenção Psicossocial: para além dos muros da loucura. Revista de Enfermagem UFPI, Teresina, v. 8, n. 3, p. 92-5, 2019. Disponível em: https://doi.org/10.26694/2238-7234.8392-95 . Acesso em: 10 Out 2020.

LANG, Regina Maria Ferreira; RIBAS, Maria Teresa Gomes de Oliveira. O nutricionista e as ações de nutrição em saúde. In: TADDEI, José Augusto C.; LANG., Regina Maria Ferreira; LONGO-SILVA, Giovana; TOLONI, Maysa Helena de Aguiar; VEGA, Juliana Bergamo. Nutrição em Saúde Pública, 2. ed. Rio de Janeiro: Rubio, 2016.

MATTOS, Ana Carolina Einsfeld; ROCHA, Luciana da Silva; RODRIGUES, Lovaine. Dialogando sobre alimentação e nutrição na saúde mental: Ações promotoras de saúde por meio de oficinas de horticultura. RASBRAN: Revista da Associação Brasileira de Nutrição, São Paulo, v. 9, n. 2, p. 17-24, jul./dez. 2018. Disponível em: https://www.rasbran.com.br/rasbran/article/view/803. Acesso em: 01 Set 2019.

MONTEIRO, Marlene Azevedo Magalhães et al. Promoção de autonomia sobre alimentação a portadores de sofrimento mental: um relato de experiência. Revista APS, São Paulo. v. 15, n. 1, p. 118-122, jan./mar. 2012. Disponível em: https://periodicos.ufjf.br/index.php/aps/article/view/14780/7887. Acesso em: 10 Out 2019. 
ORGANIZAÇÃO PAN-AMERICANA DE SAÚDE- OPAS. Sistemas alimentares e nutrição: a experiência brasileira para enfrentar todas as formas de má nutrição. Brasília, 2017. Disponível em: https://www.cfn.org.br/wp-content/uploads/2017/09/oms.pdf . Acesso em: 25 maio 2021.

PAGASSINI, Jonas Akentaon Venturineli et al. Horta terapêutica na reabilitação psicossocial dos pacientes do CAPS. Registro. 8ํㅡㄴ CONGRESSO DE EXTENSÃO, 8, Anais [...]. Marília: Universitária da Unesp, 2015.

PEREIRA, Ondina Pena; PALMA, Ana Carolina Ribas. Sentidos das oficinas terapêuticas ocupacionais do CAPS no cotidiano dos usuários: uma descrição fenomenológica.

Phenomenological Studies: Revista da Abordagem Gestáltica, Goiânia, v. 24, n. 1, p. 15 23, abr. 2018. Disponível em: http://dx.doi.org/10.18065/RAG.2018v24n1.2. Acesso em: 17 Nov 2020.

PEREIRA, Adriana Soares; SHITSUKA, Dorlivete Moreira; PARREIRA, Fábio José; SHITSUKA, Ricardo. Metodologia da pesquisa científica. Santa Maria: UAB/NTE/UFSM. 2018.

RAZZOUK, Denise. Economia da Saúde aplicada à saúde mental. In: DINIS, Mateus Mário. (org.). Políticas de Saúde Mental: baseado no curso Políticas Públicas de Saúde Mental do CAPS. Luiz R. Cerqueira. São Paulo: Instituto de Saúde, 2013. p.230-251.

ROCHA, Ludmilla Henrique de Almeida et al. Oficinas educativas para merendeiras de escolas públicas de Palmas - TO como estratégia de intervenção nutricional: um relato de experiência. Interfaces: Revista de Extensão da UFMG, Belo Horizonte, v. 8, n. 1 Edição extra, p. 209-225, maio 2020. Disponível em: https://periodicos.ufmg.br/index.php/revistainterfaces/article/view/19549. Acesso em 25 Maio 2021.

SANTOS, Ana Paula Gomes dos. Inter-relação entre saúde mental, dieta e adiposidade em adultos jovens. 2019. 309 f. Tese (Doutorado) — Programa de Pós-Graduação em Epidemiologia, Universidade Federal de Pelotas, Pelotas, 2019.

SANTOS, Lígia Amparo da Silva. Educação alimentar e nutricional no contexto promoção de práticas alimentares saudáveis. Revista de Nutrição, Campinas, v. 18, n. 5, p. 681-92, set./out. 2005. Disponível em: https://doi.org/10.1590/S1415-52732005000500011. Acesso em: 10 Out 2020.

SANTOS, Lívia Sílvia dos; HENRIQUE, Flávia Conceição dos Santos. Segurança Alimentar e Nutricional em programa de alimentação: aproximações e distâncias entre bases normativas de institucionalização. Revista Integrativa em Inovação Tecnológica nas Ciências da Saúde, Salvador, v. 3, p. 46-63, abr. 2018. Disponível em: https://doi.org/10.46635/revise.v3i00.1699. Acesso em: 12 Fev 2021.

SILVEIRA, Belisa Vieira da; SOARES, Amanda Nathale; REINALDO, Márcia dos Santos. Oficinas em saúde mental: vertentes de uma proposta de educação em saúde. Revista de Enfermagem UFPE, Recife, v. 4, n. 4, p. 1808-1814, out./dez. 2010. Disponível em: 10.5205/reuol.1153-9560-1-LE.0404201031. Acesso em: 10 Out 2020.

SOARES, Amanda Nathale; REINALDO, Amanda Márcia dos Santos. Oficinas terapêuticas para hábitos de vida saudável: um relato de experiência. Escola Anna Nery, Rio de Janeiro, v. 14, n. 2, p. 391-398, abr./jun. 2010. Disponível em: https://doi.org/10.1590/S1414-81452010000200025. Acesso em:21 Mar 2016. 
TORAL, Natacha; SLATER, Betzabeth. Abordagem do modelo transteórico no comportamento alimentar. Ciência \& Saúde Coletiva, Rio de Janeiro, v. 12, n. 6, p. 16411650, nov. 2007. Disponível em: https://doi.org/10.1590/S1413-81232007000600025. Acesso em: 21 Março 2016.

ORGANIZAÇÃO MUNDIAL DE SAÚDE - OMS. Relatório Mundial da Saúde - Saúde mental: nova concepção, nova esperança. Relatório mundial da saúde. Saúde mental: nova concepção, nova esperança. 2002. Disponível em: https://www.who.int/whr/2001/en/whr01_djmessage_po.pdf. Acesso em: 10 Out 2016.

YIN, Robert. K. 0 Estudo de caso. 5. ed. Porto Alegre: Bookman, 2014.

Os autores declaram participação na autoria conforme a Taxonomia CRediT da Casari (vide https://casrai.org/)

\begin{tabular}{|c|c|c|c|c|c|c|}
\hline Conceituação & Metodologia & Software & Validação & Análise formal & Investigação & Recursos \\
\hline$[1]$ & {$[1] /[2]$} & {$[1]$} & {$[1] /[2] /[3]$} & {$[1] /[2] /[3]$} & {$[1] /[2]$} & {$[1]$} \\
\hline Curadoria & $\begin{array}{c}\text { Primeira } \\
\text { redação }\end{array}$ & $\begin{array}{c}\text { Revisão e } \\
\text { edição }\end{array}$ & Visualização & Supervisão & $\begin{array}{c}\text { Administração } \\
\text { do projeto }\end{array}$ & $\begin{array}{c}\text { Obtenção de } \\
\text { financiamento }\end{array}$ \\
\hline$[1]$ & {$[1] /[2]$} & $\begin{array}{c}{[1] /[2]} \\
/[3]\end{array}$ & {$[1] /[2] /[3]$} & {$[1]$} & {$[1]$} & {$[1]$} \\
\hline
\end{tabular}

